\title{
Estrada-Parque Pantanal e comunidades locais na potencialização do turismo e do desenvolvimento sustentável
}

\section{Pantanal Park Road and local communities in the potencialization of tourism and sustainable development}

\author{
Marcelo Silva de Oliveira, Cleonice Alexandre Le Bourlegat
}

\begin{abstract}
RESUMO: O Pantanal, reconhecido como Reserva da Biosfera Mundial e Patrimônio Natural da Humanidade pela Unesco e como a maior planície inundável do mundo, desde 1993 passou a abrigar a Estrada-Parque Pantanal, considerada a primeira experiência desse gênero no Brasil. O objetivo desse estudo, feito entre 2014-2016, foi verificar, na escala de observação do pesquisador e numa abordagem da ecologia da paisagem, as atuais condições estruturais da Estrada-Parque-Pantanal, assim como as condições sócio econômicas e culturais de quem nela vive e atua profissionalmente na prática do turismo. $\mathrm{O}$ objeto dessa pesquisa corresponde à Estrada-Parque do Pantanal, incluindo a Área Especial de Interesse Turístico (AEIT), da qual a mesma faz parte. Foram acessadas fontes bibliográficas, estatísticas e documentais, além de uma pesquisa de campo de natureza exploratória, com enfoque no nível hierárquico mais favorável à apreciação da escala humana, na perspectiva das interações realizadas na escala horizontal ou geográfica (METZGER, 2001). O estudo permitiu verificar que grande parte dos elementos estruturais previstos na EPP não foram implantados. Por outro lado, embora a atividade turística tenha sido dinamizada e contribuído para alterar as relaçoes de trabalho, diversificar as atividades e ampliar a renda, as duas coletividades locais vivem em ambiente de risco e de exclusão social no usufruto de serviços básicos.
\end{abstract}

PALAVRAS CHAVE: Estrada-Parque; Turismo; Desenvolvimento Sustentável, Meio Ambiente.

ABSTRACT: Pantanal, recognized as a World Biosphere Reserve and a World Heritage Site by UNESCO and as the largest floodplain in the world, has since 1993 been home to the Pantanal Park Road (PPR), considered the first experience of its kind in Brazil. The aim of this study, conducted between 2014-2016, was to verify, at the researcher's observation scale and in a landscape ecology approach, the current structural conditions of the Pantanal Park Road, as well as the socio-economic and cultural conditions of those living and working professionally in tourism there. The object of this research corresponds to the Pantanal Park Road, including the Special Area of Tourist Interest (AEIT), of which it is part. Bibliographic, statistical and documentary sources were accessed, as well as an exploratory field research, focusing on the hierarchical level most favorable to the appreciation of the human scale, from the perspective of interactions performed on the horizontal or geographical scale (METZGER, 2001). The study showed that most of the structural elements provided for in PPR were not implanted. On the other hand, although tourism activity has been boosted and contributed to changing working relationships, diversifying activities and increasing income, the two local communities live in an environment of risk and social exclusion in the enjoyment of basic services. It concludes on the urgency to effect the functioning of the Management Committee.

KEYWORDS: Road Park; Tourism; Sustainable Development; Environment. 


\section{Introdução}

O Pantanal, considerado a maior planície inundável do mundo (SILVA; ABON, 1998) e espaço de convergência de diversas províncias florísticas (Amazônica, Mata Atlântica, Cerrado, Caatinga, Chaco) foi reconhecido como Patrimônio Nacional pela Constituição de 1988 e como Área Úmida de Importância Internacional pela Convenção Ramsar sobre as áreas úmidas, em 1993. Em 2000, também foi reconhecido como Reserva da Biosfera Mundial e Patrimônio Natural da Humanidade pela Unesco. O Brasil contém $70 \%$ dessa área, ou seja, 150.355 quilômetros quadrados, que tradicionalmente abriga diversos latifúndios de pecuária e algumas comunidades tradicionais que vivem sobretudo da pesca.

A consagração desses títulos ao Pantanal contribuiu para atrair fundos de financiamento internacional em prol da conservação de sua biodiversidade e desenvolvimento territorial sustentável, apoiado no turismo. Isso em parte explica a iniciativa do governo estadual, criar a Estrada-Parque Pantanal (EPP), por meio do Decreto MS no. 7.122 de 1993, considerada a primeira experiência desse gênero no Brasil. Ao longo da Estrada-Parque foram estabelecidas duas faixas laterais de 300 metros, que junto da EPP passaram a constituir a Área Especial de Interesse Turístico (AEIT).

A finalidade dessa EPP foi promover o desenvolvimento do turismo e da preservação do patrimônio cultural, numa compatibilização do desenvolvimento econômico com a conservação ambiental e o aproveitamento racional dos recursos naturais na AEIT.

Segundo Silva e Abdon (1998), a EPP cruza, de fato, quatro sub pantanais dotados de ecossistemas diferenciados: (1) o Pantanal de Miranda, caracterizado pela presença de vegetação de savana, mata e campo, com forte concentração o carandá e paratudais (Tabebuia caraiba); (2) o Pantanal do Abobral, uma das regiões mais baixas, composto por campos limpos e capões de mata esparsos; (3) o Pantanal da Nhecolândia, arenoso, rico em baias, bosques, capões, cordilheira e savanas; (4) o Pantanal do Paraguai, que corresponde à extensa planície de inundação do Rio Paraguai, com grande incidência de baías e vegetação de florestas, savanas e várias plantas aquáticas.

Além dos tradicionais latifúndios de pecuária de corte, da Área Especial de Interesse Turístico (AEIT) fazem parte duas comunidades ribeirinhas de pescadores tradicionais - a de Porto da Manga e Passo das Lontras - para onde também passarama afluir ecoturistas.

Já se passaram mais de duas décadas e são poucos os estudos que identificam a situação em que se encontra essa estrada, assim como as resultantes de sua implantação na AEIT, em relação à finalidade prevista.

O objetivo desse estudo, portanto, foi verificar, na escala de observação do pesquisador, levando-se em conta a abordagem da ecologia da paisagem, as atuais condições estruturais da Estrada-Parque-Pantanal, assim como o desenvolvimento da atividade turística e as condições sócio econômicas e culturais de quem nela vive e atua profissionalmente na prática do turismo.

O texto, além da introdução e das considerações finais, foi estruturado em três partes. Na primeira parte, é abordado o referencial teórico selecionado. Materiais e métodos são tratados na segunda parte. Por fim, são apresentados na 
terceira parte os resultados e discussões a respeito dos dados obtidos à luz do referencial teórico, na busca da resposta à questão e no atendimento ao objetivo da pesquisa.

\section{Referencial teórico}

O referencial teórico selecionado para suporte no encaminhamento do projeto de pesquisa e da análise e intepretação dos dados coletados constou basicamente, das seguintes categorias conceituais: ecologia da paisagem, estrada-parque, cuidados ambientais e manutenção de estradas-parque.

\section{Ecologia da paisagem}

O termo Ecologia de Paisagem, criado pelo biogeógrafo alemão, Carl Troll em 1939, numa busca de fusão dos conhecimentos da Geografia com aqueles da Ecologia, ganhou aceitação europeia nas décadas de 1960 e 1980 e no Brasil, a partir do final da década de 1990 e início de 2000. Na abordagem de Troll (1968) a paisagem diz respeito a uma unidade geográfica dotada de identidade específica, fruto de interações ecológicas complexas.

Uma vez estabelecido o padrão de ordem da estrutura dessa paisagem, este padrão passa a exercer um papel importante no comportamento e funcionamento da paisagem como um todo. Ao levar em conta a ecologia da paisagem em relação às heterogeneidades de paisagem no espaço e no tempo, Troll (1966) também identificou a possibilidade de se reconhecer algumas unidades mais homogêneas da paisagem em várias escalas organizativas, em termos de área e de duração do tempo de estudo.

Os adeptos dessa abordagem, passaram a verificar que as alterações de natureza humana e perturbações de regime na paisagem pode proporcionar resultados negativos para a conservação da diversidade da unidade de paisagem, especialmente se houver fragmentação e perda dos habitats (OLIVEIRA; MONTEZUMA, 2010).

Ao longo do tempo, conforme assinala WU (2013), a ecologia da paisagem acabou ganhando várias definições, de algum modo, sempre relacionadas ao conceito de Troll (1966). Entre eles, o autor destaca Isaac Zonneveld, que em 1989 adotou uma perspectiva holística na abordagem da paisagem.

Em relação ao conceito hierárquico de paisagens, Wu (2013) também se reporta como avanço, o enfoque que tem sido dado àquele nível hierárquico em que se pode identificar a escala humana, segundo ele já bastante desenvolvida na Europa e para onde grande parte dos estudos de Ecologia da Paisagem se encaminham atualmente. Nesse viés, os componentes da paisagem, numa pesquisa ecológica, deixam de ser apenas biofísicos (tangíveis), para serem considerados aqueles das dimensões intangíveis ou culturais. Desse modo, tenta-se apreciar e integrar as diferentes perspectivas multidimensionais nessa relação entre cultura e natureza. Isso significa também que a abordagem

Um outro aspecto desse avanço para um conceito mais holístico e interdisciplinar da Ecologia da Paisagem, para Wu (2010) é o de se considerar além das paisagens naturais, as paisagens seminaturais, agrícolas e urbanas. Nesse aspecto, o autor realça a importância que passaram a ter as características culturais 
da paisagem, uma vez que ela reflete a relação interativa da cultura com a natureza e dotada de significados. Nesse caso, a cultura foi o agente e o natural o meio, tendo como resultado a paisagem cultural. Esse conceito já foi utilizado na Convenção do Patrimônio Cultural e Natural do Mundo pela Unesco em 1992, considerado sob três manifestações: (1) aquelas claramente definidas e projetadas intencionalmente por humanos (Ex. jardins e parques); (2) aquelas que resultam de interações sucessivas entre pessoas e seu ambiente natural; (3) aquelas que possuem poderosas associações religiosas, artísticas ou culturais com os elementos naturais, nesse caso sem ser integralmente criadas pelos seres humanos (WU, 2010).

Nessa nova perspectiva integrada da Ecologia da Paisagem, a tendência, segundo Menegat e Porto (2004), tem sido a de abordar as interações da paisagem em duas dimensões: uma no plano horizontal e, outra, no vertical. Na dimensão horizontal a abordagem é mais geográfica, procurando-se compreender as interações dos fenômenos naturais e humanos no espaço. Na dimensão vertical, a abordagem é mais ecológica, num estudo de interações funcionais de um determinado lugar. Na abordagem de Metzger (2001) a dimensão geográfica leva em conta a influência do homem sobre a paisagem e a gestão do território, enquanto a ecológica valoriza mais o contexto espacial sobre os processos ecológicos, e a importância destas relações em termos de conservação biológica. A definição integrada aborda a paisagem como sendo um conjunto heterogêneo constituído de unidades interativas que pode ser apreendida pelo observador numa determinada escala de percepção (METZGER, 2001). Essa escala de análise, segundo esse autor, favorece mais os trabalhos aplicados à resolução de problemas.

\section{Estrada-Parque}

O conceito de Estrada-Parque nasceu em 1935, da iniciativa norte-americana de criação da Blue Ridge Parkway, na conexão de dois grandes parques, o Great Smoky Mountains National Park e o Shenandoah National Park, visando proteger a beleza cênica e ainda se tornar uma frente de trabalho (SORIANO, 2006). Esse país vivia a crise econômica de 1929, causada pela quebra da Bolsa de Nova lorque, de modo que a abertura da estrada também abria oportunidade de emprego para as famílias empobrecidas dessas áreas de montanha (TIAGOR; PIRES, 2010).

Para Forman (1986), o conceito de Estrada Parque vem da terminologia "parkway", criada no século XIX por Calvert Vaux e Frederick Law Olmsted, utilizada para identificar uma estrada usada para contemplação da paisagem. Em 1991, foi criado nos EUA o National Scenic Byways Program, com a finalidade de colocar em destaque $o$ conjunto já existente de estradas cênicas com suas histórias e lugares interessantes. A estrada-parque ganhou destaque nesse programa, em função de suas particularidades, sejam arqueológicas, culturais e históricas, como também por serem dotadas de áreas naturais e de recreação de grande potencial cênico (XIMENES, 2013, p.51). Observe-se que nessa concepção de estrada-parque construída pelos norte-americanos, sua beleza cênica, mais particularmente, o panorama visto a partir dela, eram levados em conta, numa ideia preservacionista do meio ambiente.

No Brasil, esse termo "Estrada-Parque" vem sendo interpretado de forma, nem sempre coincidente com a concepção norte-americana. A Lei do Sistema Nacional de Unidades de Conservação (SNUC), criada em 2000, não previu as 
estradas-parque como categoria. A Área de Proteção Ambiental é a categoria de proteção que mais se adequa à estrada-parque. No entanto, algumas legislações estaduais já a incluíram, como é o caso de Mato Grosso do Sul, Mato Grosso, Rio Grande do Sul, Tocantins e Amazônia e as definem institucionalmente. Além disso, Soriano (2006) apontou para definições apresentadas em outros documentos, tais como na fase 2 do Plano para o SNUC (1982) e seu vocabulário (2002), na Fundação S.O.S Mata Atlântica (2004) e no Manejo de Áreas Silvestres de Santa Maria/RS (1996). Observando-se essas diversas definições institucionais, trazidas por Soriano (2006), pode-se verificar que, de modo geral, a Estrada-Parque vem sendo concebida como parque-linear de valor panorâmico, cultural e de lazer, que inclui o leito da rodovia e faixas laterais, podendo se manifestar tanto em áreas de domínio público como privado.

De acordo com Soriano (2006), a Estrada-Parque se caracteriza por ser uma área de conservação de grande beleza cênica, destinada à recreação e lazer, a ser protegida e na qual de deve promover o desenvolvimento sustentável, numa integração homem-natureza.

\section{Cuidados ambientais na construção e manutenção de estradas-parque}

As Estradas-Parque, conforme assinalam Ribeiro e Lima (2017), são vias especiais, com padrão diferenciado de projeto, construção e operação, em relação às rodovias tradicionais. De modo geral, segundo esses autores, adota-se um conjunto de critérios ambientais e equipamentos e serviços particulares, como zoopassagens, telas de proteção, pátios para contemplação, portais, entre outros. Além disso, os autores lembram que elas requerem um conjunto de atributos, capazes de garantir um tráfego seguro e confortável a quem delas se utilizam. Dessa preocupação fazem parte, por exemplo, a geometria e o traçado da via, assim como raios de curvatura, inclinações e concordâncias, distâncias de visibilidade. Ainda são padronizadas de formas ajustadas, as faixas de domínio, faixas de tráfego e acostamentos, para não comprometer ambientes frágeis da unidade (RIBEIRO; LIMA, 2017) .

Numa estrada-parque o volume de tráfego e a velocidade operacional geralmente são menores. Os veículos mais leves tendem a ser os mais apropriados, pois ocupam menor superfície, reduzindo os riscos de fragmentação e o ressecamento de borda, alterações no balanço hídrico e facilitam a perambulação de animais silvestres (RIBEIRO; LIMA, 207). A implantação da Estrada-Parque, conforme assinalam Dutra et al (2008), pode provocar também um forte aumento dos fluxos turísticos com impactos negativos à comunidade.

Trichês et al. (2011) lembram que, no Brasil, a preocupação ambiental com a construção de estradas manifestou-se desde 1981, frente à exigência da Lei Federal 938 para elaboração de Estudo de Impacto Ambiental (EIA). A partir de 2000, também surgiram estudos voltados à certificação de estradas, consideradas "rodovias verdes". Para esse tipo de enquadramento, segundo esses autores, é preciso comprovar ao longo da estrada, a conservação da flora e da fauna, a proteção de mananciais, sua integração à paisagem, num respeito à história e às comunidades locais. Nela se faz uso de materiais lindeiros, matéria-prima reciclada ou subprodutos da indústria. Ainda se minimiza o consumo de energia e de emissões de gazes em sua construção e manutenção e operação. Essa estrada também se mostra segura, confortável e econômica ao usuário. 


\section{Materiais e métodos}

O objeto dessa pesquisa corresponde à Estrada-Parque do Pantanal, incluindo a Área Especial de Interesse Turístico (AEIT), da qual a mesma faz parte.

Os estudos foram realizados entre os anos de 2015 e 2016. A pesquisa foi iniciada por meio do acesso aos dados disponíveis de fontes secundárias (bibliográficos e documentais). A revisão bibliográfica a respeito dos elementos que integram o tema e o objeto pesquisado da pesquisa, permitiram selecionar as principais teorias e categorias conceituais. O levantamento de fontes documentais e estatísticas deram suporte na identificação dos vários aspectos da realidade do objeto de pesquisa.

A pesquisa de campo foi de natureza exploratória, envolvendo visitas de imersão na área de estudo durante os anos de 2014-2016, não só para observar as situações concretas e vivenciais, como para se familiarizar com elas e dialogar com as pessoas que vivem na AEIT. O enfoque foi dado ao nível hierárquico da paisagem que melhor permite apreciar a escala humana nas complexas interações ecológicas. A apreciação foi feita na perspectiva das interações no plano horizontal que, conforme Metzger (2001), leva em conta as ações do homem na paisagem e a gestão do território. Trata-se de uma escala de análise mais favorável, quando se busca a resolução de problemas.

\section{Resultados e Discussão}

\section{Contexto em que emergiu a Estrada-Parque Pantanal}

Além dos títulos recebidos, um conjunto de variáveis de natureza econômica e ambiental, como a crise da pecuária na década de 80 , associada a um momento de valorização do turismo de pesca e de contemplação e aos movimentos em prol da conservação do ambiente pantaneiro, concorreu para a iniciativa do governo de Mato Grosso do Sul de criar a EPP no Pantanal.

Há mais de dois séculos, segundo Alho e Lacher (1991, apud Harris et al, 2011), a pecuária extensiva de gado de corte em grandes latifúndios transformara-se na atividade predominante no Pantanal. Além dessas propriedades rurais, o Pantanal, em seu todo, conta com a presença de algumas coletividades ribeirinhas que vivem especialmente da pesca e que oferece mão-de-obra de apoio às fazendas de gado.

As práticas do turismo de pesca, iniciada desde os anos 70 do século $X X$, foram bem recebidas como atividade complementar da pecuária (RIBEIRO; VARGAS; ARAÚJO, 2011). Segundo essas autoras, tais atividades se consolidaram particularmente a partir da década de 80 , especialmente em função da melhoria das condições de infraestrutura de transporte. Pousadas rústicas de administração familiar foram emergindo, com a finalidade de abrigar o turismo de pesca. Nesse período também ocorreram as primeiras iniciativas de construção de estruturas para recepção de turistas interessados na pesca esportiva.

Em 1986, com o término da ampliação da BR-262 até Corumbá-MS, esta passou a canalizar o fluxo de transportes, antes realizado apenas pelas rodovias estaduais MS-184 e a 228. Desse modo, o fluxo mais importante foi desviado para a BR-262, enquanto as duas outras tradicionais rodovias passaram a servir de uso mais exclusivo dessa região atendida por elas. Isso significava os produtores rurais, 
os empreendimentos turísticos já implantados e ainda turistas que pretendiam adentrar as áreas pantaneiras para contemplar a beleza de suas paisagens.

No final da década de 1980, a região atraiu a atenção de ONGs ambientalistas internacionais, a exemplo da World Wildelife Funs (WWF) e Conservation International $(\mathrm{Cl})$, para apoiar o governo em ações de planejamento que se voltassem à conservação ambiental do Pantanal, com apoio de universidades regionais. Dentre as iniciativas desse planejamento esteve a proposição da Estrada-Parque Pantanal (EPP) na rota das já existentes rodovias MS-184 e MS-228. A EPP acabou sendo criada em 1993, pelo decreto estadual no. 7.122. Dela passou a fazer parte duas faixas de 300 metros em cada lado da estrada, em quase toda sua extensão. Esse conjunto da rodovia e faixas laterais, com área total de $6.800 \mathrm{~km} 2$, foi definido, segundo Soriano (2006), como Área Especial de Interesse Turístico (AEIT).

A EPP tem seu início no entroncamento da BR-262 com a MS-184, no local denominado "Buraco das Piranhas", até a localidade conhecida como "Curva do Leque". A partir de então, incorpora a estrada MS-228 do trecho entre a fazenda Alegria, passando pelo Porto da Manga. Nesse ponto, a travessia do rio Paraguai é feito por balsa e pela Morraria do Urucum. A Estrada-Parque termina no Lampião Aceso, um posto fiscal localizado junto da BR-262.

Dos 127 quilômetros de extensão, 90 quilômetros da EPP foram ajustados sob aterros de um a três metros de altura em relação ao leito natural do Pantanal. Ainda foram construídas 74 pontes de madeira, para dar maior vazão aos corixos ${ }^{1}$, lagoas e vazantes durante o período das cheias anuais.

\section{O desenvolvimento das atividades turísticas na AEIT}

O Pantanal, conforme assinalado, começou a ser divulgado e a atrair turistas, ainda na década de 1970, em função de sua grande quantidade e variedade de peixes. As fazendas pantaneiras, que antes viviam basicamente da pecuária extensiva, vislumbraram na atividade turística dessa natureza uma forma de complementaridade econômica (RIBEIRO; VARGAS; ARAÚJO, 2011). Nesse sentido, parte dos fazendeiros passou a reestruturar suas propriedades para recepção de turistas interessados na pesca esportiva.

Surgiram assim os primeiros ranchos de pesca, áreas para camping e pousadas. $\mathrm{Na}$ década seguinte, as estruturas tornaram-se mais complexas, envolvendo práticas do turismo contemplativo, atividades que também atraíram investidores de fora da região. Dessas iniciativas, surgiram investimentos, tais como pousadas, hotéis, pesqueiros. Alguns deles criaram estruturas como piscinas, espaços reordenados para passeios a cavalo, trilhas ecológicas, para safaris fotográficos como também de passeios de barco. Também surgiram empreendimentos sob forma de barco-hotel, para usufruir da pesca e contemplação diretamente nos rios. Turistas passaram a afluir de várias partes do país e internacionais.

Nesse processo, conforme assinalaram Ribeiro, Vargas e Araújo (2011), os fazendeiros passaram a ocupar e preparar seu próprio pessoal dentro da propriedade rural na recepção dos turistas, seja como guia, camareira, cozinheira, faxineira, garçom, entre outros. As relações evoluíram para o assalariamento, quase sempre somadas às gorjetas dos turistas. Nesse sentido, a atividade turística 
passou a contribuir para alterar, de certo modo, as as relações de trabalho praticadas anteriormente, resultando em melhoria de renda não só dos fazendeiros como da mão-de-obra ocupada para essa atividade. Todas essas mudanças vêm proporcionando novas condições na vida aos integrantes das coletividades tradicionais locais, como por exemplo, "redirecionamentos socioeconômicos, aprendizagem de novas técnicas e construção de novas relações com a natureza e a coletividade" (RIBEIRO, 2014, p. 111). Na década de 1990, as estruturas construídas para a a recepção de turistas no Pantanal já haviam se tornado mais complexas, associando a pesca ao turismo contemplativo (MORETTI, 2000). A estrutura hoteleira instalada, ao longo do tempo na EPP passou a contribuir para potencializar o turismo local. Existem quatro pousadas voltadas à prática do ecoturismo, que permanecem ao longo da EPP. Para a prática da pesca, também existem quatro estabelecimentos hoteleiros às margens do rio Miranda.

As duas coletividades ribeirinhas tradicionais de pescadores presentes na AEIT- Porto da Manga e Passo dos Lontras - que se mantinham até então, vivendo da pesca, num tipo de vida até certo ponto isolada, acabou sendo atingida pelos efeitos da atividade turística, especialmente a partir da década de 1990. A prática do turismo local levada a efeito pelas fazendas e infraestrutura hoteleira, associada à melhoria na infraestrutura da comunicação com áreas externas (rádio, TV, telefone, internet, celular) significaram novas oportunidades de trabalho. Muitos dos pescadores tradicionais dessas localidades migraram para a atividade turística, entre outros, para exercer a função de pescadores, coletores de iscas, piloteiros, guias, ou trabalhadores em hotéis e pousadas da região.

A dinamização do turismo nessas duas localidades também tem contribuído para atrair novos moradores, vindos especialmente das cidades próximas como Corumbá, Miranda, Aquidauana. Segundo dados populacionais do Censo do IBGE, em 2010, viviam nessas duas localidades, 647 pessoas, sendo 383 delas na comunidade do Porto da Manga e 264 na comunidade do Passo das Lontras.

O Pantanal foi eleito em 2016 o quarto melhor destino para apreciação de vida selvagem no mundo, numa votação promovida por um dos principais portais de notícias dos Estados Unidos, o USA Today (MINISTÉRIO DO TURISMO, 2016). De acordo com o Observatório de Turismo de Corumbá, a região pantaneira desse Município recebeu em 2015, mais de 52.045 pescadores esportivos. Dentre eles, $25 \%$ usufruíram da Estrada-Parque Pantanal junto às localidades do Porto da Manga e Passo das Lontras.

Os quatro pantanais atravessados pela EPP mudam suas paisagens em função da periodicidade das enchentes. No período das cheias, a água inunda os campos, unindo lagoas e corixos, transformando a paisagem em uma imensa área alagada. Já no período das vazantes, os peixes ficam confinados nos corixos e se tornam alimentos abundantes para diversos animais, sobretudo as aves, tais como tuiuiús, garças, cabeças-secas. Se de um lado a pesca esportiva ainda tem se configurado como a atividade mais importante na Estrada-Parque, de outro o foco da contemplação turística se volta para esse grande conjunto faunístico presente na paisagem. 


\section{Estrada-parque Pantanal e suas atuais condições estruturais}

A maior preocupação dos gestores públicos para manter o funcionamento da EPP tem sido sua infraestrutura de acesso, uma vez que ela fica comprometida durante o período das cheias. Para tentar garantir o tráfego de automóveis e caminhões, a maior atenção tem sido na manutenção do leito e das pontes de madeira, seja para garantir o fluxo de turistas, como o escoamento da produção do setor pecuário local. A pecuária ainda é a atividade econômica mais importante da região pantaneira e nela ocorrem diversos leilões de gado. Esse escoamento do gado das fazendas envolve grande quantidade de caminhões. As estimativas são as de que cerca de $60 \%$ desse gado leiloado na região passem pela EPP, transportados por caminhões boiadeiros.

As 74 pontes de madeira na EPP, que cruzam corixos, rios e vazantes, suportam diversas naturezas de carga, sendo submetidas a enchentes, queimadas e ao desgaste natural pelo uso. A manutenção dessas pontes tem representado gastos constantes aos cofres públicos. É importante assinalar que elas exigem madeiras de árvores regionais de grande porte, muitas vezes centenárias, cuja retirada da mata, pode comprometer sua sustentabilidade.

Ainda não foram implantadas na Estrada-Parque do Pantanal muitos dos elementos previstos no Decreto 7.122/93 para compor sua estrutura. Pode-se citar nesse caso o centro de atendimento ao turista, as guaritas, os pórticos, os marcos, os mirantes, as passarelas, as estruturas para observação da fauna, a base de apoio para Polícia Ambiental. Inexistem locais estratégicos para contemplação da paisagem ou observação de animais, que possam proporcionar conforto e segurança ao turista. Espécies invasoras das margens da estrada, tais como o saranzinho (Sesbania virgata) e o espinheiro-preto (Mimosa Weddiliana) e/ou outros arbustos, geralmente dificultam essa contemplação.

A precariedade da comunicação, sinais de telefonia e internet, também tem sido um fator limitante da atividade turística e dos mecanismos de gestão, assim como os serviços básicos destinados aos moradores das comunidades locais.

Vargas e Heemann (2003) assinalam que, por meio de propagandas turísticas veiculadas por diversas organizações, constroem-se mitos acerca do ambiente e da paisagem na EPP que, de fato, não correspondem à realidade. As empresas nela envolvidas, segundo Moretti (2000) vendem a ideia de natureza preservada e disponível para ser apreciada, o que nem sempre se verifica.

No entanto, a bióloga D’Abra (2014) lembra que as as próprias condições de uso da estrada têm contribuído para a constante perda de espécies por atropelamento. De fato, é visível, por quem passa pela estrada, a grande quantidade de carcaças de animais mortos em faixas de rolamentos e acostamentos. Tais atropelamentos, conforme lembra a autora, criam problemas relativos ao isolamento e perda de variabilidade genética, eventualmente ocasionando extinções locais e regionais. Além disso, D'Abra (2014) assinala que a área se torna mais sujeita a fenômenos como dispersão de espécies invasoras, alterações de ciclos hidrológicos, mudanças microclimáticas, poluição atmosférica, produção de ruído, perda e degradação de habitats e fragmentação de ambientes. Por outro lado, como essa estrada foi construída sobre aterros que variam entre um a três metros de altura e atravessa diversos ecossistemas do Pantanal, ela tende a se constituir em uma via de deslocamento dos animais nos meses de cheias, para buscar as partes mais altas como refúgio. Esses animais acabam entrando em conflito com o fluxo de veículos, o que resulta em frequentes atropelamentos (D'ABRA, 2014). 


\section{Cultura histórica e arqueológica incorporada na paisagem do AEIT}

É preciso lembrar que a AEIT também traz incorporada em sua paisagem, construções que materializam aspectos da cultura histórica do lugar, que exigem trabalhos mais ajustados por sua conservação. Ao final do conflito da Guerra contra o Paraguai, em 1870, foi implantada no Porto da Manga a linha e a Estação de Telégrafos, conectando Corumbá ao território nacional. Na margem direita do rio Paraguai, em 1904 foi erguida por Marechal Rondon, sob palafitas, a casa do guarda-fios, destinada aos serviços de inspeção e reparação dos fios e dos postes dessa linha. Essa localidade também fora utilizada pelos fazendeiros da região para montar uma indústria de charque, visando o abastecimento do mercado interno e externo após a I Guerra Mundial.

Dentre esses bens culturais, depois da passagem da EPP, apenas a Casa do Guarda-Fios foi restaurada. Nela foi proposto um museu, mas até o presente ainda não concretizado.

O Pantanal também conta, segundo Banducci (2003), com diversos sítios arqueológicos e paleontológicos abertos à visitação pública, integrados ao projeto Geopark, que busca o credenciamento da UNESCO. Do ponto de vista imaterial, pode-se referir a obras que se identificam fortemente com o ambiente pantaneiro, a exemplo das músicas do conhecido cantor e compositor Almir Sater, com destaque ao "Trem do Pantanal" e as obras literárias de reconhecimento internacional do poeta Manoel de Barros.

\section{Condições socioeconômicas e ambientais das duas coletividades ribeirinhas na $A E I T$}

As duas coletividades ribeirinhas de pescadores tradicionais na AEIT, Passo das Lontras e Porto da Manga, emergiram historicamente da construção e uso de "manga", uma espécie de curral que serve de suporte à estadia do gado em locais de travessia do rio. Observa-se que mesmo após se verificar melhorias de renda dessas famílias na atividade turística, essas duas coletividades vivenciam problemas ambientais que afetam a qualidade de vida em seus locais de moradia.

\section{Passo do Lontra}

A coletividade do Passo do Lontra emergiu da construção e uso da "manga", que serve de suporte à estadia do gado do Pantanal do Abobral e Nhecolândia para transpor o rio Miranda, complementando essa atividade com a pesca profissional artesanal. Desde a década de 1970, diante das novas condições de transporte e comunicação, os moradores se voltaram ao atendimento da pesca esportiva, exercendo a função de piloteiros, guias de pesca, coletores de isca e funcionários das pousadas vizinhas.

O local, por sua localização junto à BR-262, passou a servir de ponto de parada, assim como posto de informação, referência e apoio a pescadores e ecoturistas que têm a região como destino.

Os moradores, sempre sujeitos às enchentes anuais, vivem em casas de madeira sobre palafitas, em estado precário, para as quais o acesso é feito por passarelas improvisadas. A falta de quintais dificulta a possibilidade da criação de 
animais, ou de árvores e hortaliças. Desse modo, fora da pesca, praticamente inexistem gêneros alimentícios produzidos no lugar.

Na maioria das residências, o consumo de água é proveniente do rio Miranda. A água é bombeada para as caixas d'água e ali tratada com cloro. Como inexiste serviço de saneamento básico, os dejetos são lançados in natura no rio por parte das habitações. A coleta de lixo é realizada uma vez por semana pela prefeitura de Corumbá. Os resíduos não coletados acumulam-se principalmente debaixo das casas, causando efeitos maléficos. A população convive com o mau odor, poluição visual e degradação no meio em que vivem. Correm frequentemente o risco de queda das passarelas nas águas contaminadas pelos dejetos lançados in natura por parte das habitações.

Em 1987, a Universidade Federal de Mato Grosso do Sul implantou uma Base de Estudos do Pantanal (BEP/UFMS), e passou a ceder parte de sua estrutura à Secretaria Municipal de Educação de Corumbá para oferta do ensino fundamental e de serviços de um ambulatório médico e odontológico, com apoio dos acadêmicos dos cursos de medicina, farmácia e odontologia da UFMS. Mas a comunidade é carente dos outros serviços importantes, como serviço postal e transporte.

Mesmo diante dessas dificuldades de bem-estar social e ambiental na forma de viver coletivamente, foi construído ao longo do tempo, um ambiente de sociabilidade entre os moradores do Passo do Lontra. Estes costumam se reunir e conversar debaixo de uma frondosa figueira, localmente denominada de "Pau da Fofoca", sentando-se sobre uma tora. A única mercearia de secos e molhados também tem servido de ponto de encontro. O bar "Sovaco de Cobra" que serve de atividade complementar à pesca profissional por seu proprietário, se constituiu no único estabelecimento de lazer noturno. As expressões artísticas da comunidade se revelam especialmente, no artesanato de madeira e na arte em miçangas, inspiradas, sobretudo na fauna local. A religiosidade também se manifesta por meio dos altares construídos nas duas margens do rio Miranda, em homenagem a Nossa Senhora Aparecida, como pela festa por sua devoção todo dia 12 de outubro.

Os moradores se identificam com a velha ponte de madeira construída há um bom tempo e lutam por sua permanência, mesmo depois de construída a nova ponte em alvenaria. A altura da velha ponte restringe a passagem de barcos maiores, como os barcos-hotel de grande porte, o que proporciona maior preservação do potencial pesqueiro no local, como também a manutenção das atividades exercidas pelos moradores e empresários instalados no lugar.

\section{Porto da Manga}

A coletividade que vive no Porto da Manga emergiu desde o século XIX, numa localidade escolhida para abrigar a "manga" que serve de suporte à travessia gado pelo rio Paraguai, em direção à Fazenda Terra Firme (BARROS, 1998).

A exemplo da outra coletividade, o Porto da Manga ganhou novo dinamismo a partir de 1970, com a prática do turismo de pesca. O Hotel ali instalado, com 80 leitos e oferta de serviço completo aos hóspedes, aparece como uma das opções de trabalho para parte dos moradores. Dentre outras atividades exercidas para essa modalidade de turismo, segundo a ECOA (2008), a coleta de iscas vivas tem sido a maior geradora de trabalho e renda, embora resulte em grandes impactos na saúde dos isqueiros. Estes permanecem aproximadamente 8 horas dentro da água dos 
corixos, especialmente à noite, suscetíveis a doenças pulmonares e dermatites e, no caso das mulheres, também a doenças ginecológicas.

A coletividade, mediante apoio de uma ONG, iniciado em 2001, começou a ser treinada para exercer a prática do manejo sustentável na armazenagem das iscas coletadas. Esse apoio da ONG também se estendeu às mulheres, que criaram a Associação das Mulheres Extrativistas do Porto da Manga. A partir dessa associação surgiram algumas iniciativas vinculadas à atividade turística, com base em recursos locais. Uma delas foi a "cozinha comunitária", que permitiu, por exemplo, a produção do doce de laranjinha-de-pacu, fruta abundante em Porto da Manga. Passou-se à elaboração de artesanatos, como aqueles feitos com a fibra de aguapé - Eichornia crassipes, também conhecido por camalote, planta abundante nos rios da região.

No entanto, os relativos avanços econômicos que passaram a ocorrer entre os moradores do Porto da Manga, da mesma forma que o Passo das Lontras, pouco tem sido acompanhado de melhoria das condições vividas no ambiente local.

Os antigos moradores, de modo geral, vivem nas áreas mais altas e em melhores condições de moradias, quase sempre de alvenaria, junto a quintais com cultivos de subsistência. Já os moradores mais recentes e de menor poder aquisitivo encontram-se nas áreas mais baixas, sujeitas a situações mais precárias.

Essa coletividade do Porto da Manga também não usufrui de infraestrutura adequada de saneamento básico e nem para oferta de água potável. A energia elétrica chegou apenas em 2007, por meio do projeto federal "Luz Para Todos". A coleta de lixo só foi disponibilizada, mediante Termo de Ajustamento de Conduta firmado entre o Ministério Público Federal do estado de Mato Grosso do Sul e Prefeitura de Corumbá. Anteriormente, o lixo local era incinerado, atingindo Áreas de Preservação Permanente, o que acarretava sérios danos ambientais (MPF, 2015).

O serviço de educação escolar às crianças da comunidade funciona precariamente em duas salas alugadas pelo Prefeitura de Corumbá do único hotel ali instalado. Inexistem serviços de transporte e saúde pública. Em determinadas épocas do ano, dependendo da altura das águas, só é possível a saída do lugar por meio de barcos.

\section{Comitê Gestor da AEIT}

Um Comitê Gestor da Área Especial de Interesse Turístico da Estrada-Parque do Pantanal, de natureza consultiva e deliberativa, acabou sendo criado pelo estado de Mato Grosso do Sul, por meio da Lei 9.985/2000 e, posteriormente reorganizado pelo Decreto 13.412 de 2012, com ações geridas pelo Instituto de Meio Ambiente de Mato Grosso do Sul (IMASUL, 2016).

O objetivo do comitê passou a ser o de assegurar a preservação e valorização do patrimônio cultural e natural e, ao mesmo tempo, estabelecer normas de uso e ocupação do solo na AEIT. Os novos membros do comitê ganharam atribuições, portanto, de deliberar sobre as normas e limites das zonas da Estrada Parque Pantanal, assim como sobre o sistema de sinalização da EPP, além da zelar pelas informações e publicidade sobre a AEIT. O Comitê ainda poderia acionar Câmaras Técnicas e consultores credenciados, no caso de discussão de projetos, da necessidade de estudos e pesquisas, procurando reforçar o processo 
participativo, envolvendo prefeitura, empresas, associações, universidades, entre outros.

$\mathrm{Na}$ época, o novo presidente havia assinalado que o foco da gestão estaria concentrado no desenvolvimento do turismo, humano e ambiental e que as iniciativas seriam construídas com a participação dessas organizações e da coletividade local.

No entanto, seu funcionamento ainda não se deu de forma efetiva. Até o período da pesquisa, esse comitê gestor ainda não contava com diagnóstico detalhado sobre essa região, como também não havia qualquer proposta de plano diretor e plano de manejo, instrumentos considerados fundamentais para esse fim.

\section{Considerações finais}

O presente estudo permitiu considerar que, no conjunto, os objetivos iniciais previstos na criação da EPP em 1993 e estabelecidos posteriormente pelo seu comitê gestor em 2000, retomados em 2012, ainda estão um pouco longe de serem cumpridos.

O que se pôde avaliar de forma, até certo ponto positiva, como impacto da criação da EPP, tem sido o relativo crescimento da infraestrutura da atividade turística, já deflagrado antes da criação da estrada, mas que se tornou mais complexa e tem conseguido atrair um grande número de turistas de origem nacional e internacional.

Vinculado a esses avanços da atividade turística, da construção da EPP e da melhoria dos meios de comunicação, também se pode creditar as mudanças ocorridas nas relações de trabalho, diversificação de atividades e ampliação de renda para os integrantes das coletividades e fazendeiros locais. Essa situação, até certo ponto, também se constituiu em oportunidades de negócios turísticos para empreendedores externos.

No que tange às condições estruturais da estrada, pôde-se avaliar que muitos dos elementos previstos desde 1993 para o usufruto de turistas, não foram cumpridos, seja para garantir a informação, seja para proporcionar segurança e conforto à contemplação da paisagem e observação de animais, entre outros. Além disso, vivencia-se os impactos motivados pelo intenso trânsito, especialmente na época das chuvas, levando-se em conta que a EPP também é utilizada para o escoamento do gado das fazendas locais. Soma-se a isso, a necessidade de melhoria dos meios de comunicação, que limitam a atividade turística.

Ainda que as duas coletividades ribeirinhas tradicionais tenham usufruído do dinamismo da atividade turística no local, o mesmo não ocorre de forma adequada em relação às suas condições de moradia e à oferta de serviços básicos de infraestrutura física (água, energia, saneamento básico) e social (educação, saúde).

Os elementos culturais que fazem parte da paisagem da AEIT, por seu turno, não têm recebido a merecida atenção no seu processo de conservação e valorização.

Embora na EPP existam duas bases científicas de estudos do Pantanal - a Embrapa Pantanal e a Base de Estudos do Pantanal (BEP/ UFMS) - as pesquisas sobre as atividades relacionadas a Estrada-Parque Pantanal têm sido pouco expressivas. 
Verifica-se, portanto, grande urgência no efetivo funcionamento do Comitê Gestor já criado, na forma como foi idealizado, para se estabelecer dispositivos de gestão e se repensar o modelo de unidade protegida da Estrada-Parque Pantanal. Ele se constitui no meio mais eficaz para se promover um desenvolvimento territorial sustentável, que leve em conta, não só a dimensão econômica e ecológica, mas também social e cultural.

No entanto, as ações estratégicas devem se voltar com maior agilidade, não só para a estruturação da EPP, como para retirar os integrantes das duas coletividades do ambiente de risco em que vivem, mediante participação mais ativa dos mesmos, com apoio das organizações previstas.

\section{Referências}

BANDUCCI Jr., A. Turismo cultural e patrimônio: a memória pantaneira no curso do rio Paraguai. Universidade Federal de Mato Grosso do Sul/ Brasil. Horizontes Antropológicos, Porto Alegre, ano 9, n. 20, p. 117-140, outubro de 2003.

BARROS, A.L. Gente Pantaneira (crônicas de sua história). Lacerda Editores, 1998. BRASILEIRO, M.D.S.; MEDINA, J.C.; CORIOLANO, L.N. (orgs). Turismo, cultura e desenvolvimento. Campina Grande: EDUEPB, 2012. 240 p. Disponível em: http://www.sba1.com/sobre-o-sba

D'ABRA, F. Atropelamento de fauna: desastre ambiental fácil de evitar. Disponível em: http://www.oeco.org.br/colunas/colunistasconvidados/28467atropelamento-de-fauna-desastre-ambiental-facil-de-evitar/ . 01 julho 2014 . Acesso: 28/10/2016

DIEGUES, A.C.S.A. 0 mito moderno da natureza intocada. $3^{\underline{a}}$ ed. São Paulo: Hucitec Núcleo de Apoio à Pesquisa sobre Populações Humanas e Áreas Úmidas Brasileiras, USP, 2001.

DUTRA, V.; COlARES, A.; ADORNO, L. F. M.; MAGALHÃES, K.; GOMES, K. Proposta de estradas parque como unidade de conservação: dilemas e diálogos entre o Jalapão e a Chapada dos Veadeiros. Sociedade \& Natureza, Uberlândia, 20 (1): 161-176. Junho de 2008.

ECOA. ECOLOGIA E AÇÃO. Iscas vivas - transformando as comunidades do Pantanal mato grosso do sul. Disponível em: http://riosvivos.org.br/wpcontent/uploads/2015/08/iscasvivas.pdf. março 2008

EMBRAPA, Pesquisa e Desenvolvimento, recursos pesqueiros. 2006. Disponível em https://www.embrapa.br/pantanal/recursos-pesqueiros . Acesso em: 12 agosto 2016

FUNDAÇÃO DE TURISMO DE MATO GROSSO DO SUL. Brasil é o primeiro no ranking Turismo de Aventura e MS é referência no segmento. Disponível em: http://www.turismo.ms.gov.br/brasil-e-o-primeiro-no-ranking-turismo-de-aventura-ems-ereferencia-no-segmento/ . Acesso em: 3 setembro 2016.

GIRARD, P.; VARGAS, I.A. Turismo, desenvolvimento e saberes no Pantanal: diálogos e parcerias possíveis. In: II Colóquio Internacional de Desenvolvimento Local, realizado em Campo Grande UCDB, 29 a 31 de agosto de 2007.

GOIS, C.W.L. Psicologia comunitária: atividade e consciência. Fortaleza: Instituto Paulo Freire, 2005. 
HARRIS, M.; TOMAS, W.; MOURÃO, G.; SILVA, C.; GUIMARÃES, E.; SONODA, F.; FACHIN, E. Desafios para proteger o Pantanal brasileiro: ameaças e iniciativas em conservação. In: Megadiversidade, ano 1, vol. 1, p. 156-165, julho de 2005.

LE BOURLEGAT, C.A. Sustentabilidade Local. IV Simpósio Sobre Recursos Naturais e Sócio-Economicos do Pantanal - Corumbá/MS nov 2004.

MENEGAT, R.; PORTO, M;L; Ecologia de Paisagem: um novo enfoque na gestão dos sistemas da terra e do homem. In Desenvolvimento sustentável e gestão ambiental nas cidades: estratégias a partir de Porto Alegre. (Orgs) Rualdo Menegat e Gerson de Almeida. Porto Alegre: Edufrgs, pp. 361-376, 2004

METZGER, J.P. O que é ecologia de paisagens? In: Biota Neotrópica. Vol. 1 (1), 2001, p. 1-9.

MINISTÉRIO DO MEIO AMBIENTE. Cadastro Nacional de Unidades de Conservação. Disponível em : http://www.mma.gov.br/areas-protegidas/cadastronacional-de-ucs

MINISTÉRIO DA JUSTIÇA E CIDADANIA. Politicas de Promoção da igualdade racial. Comunidade Tradicionais 0 que são. Disponível em: http://www.seppir.gov.br/comunidades-tradicionais/o-que-sao-comunidades-

tradicionais . Acesso em: 10 agosto 2016.

MORETTI, E.C. Ecoturismo. In III Simpósio sobre Recursos Naturais e Socioeconômicos do Pantanal, Corumbá, 27 a 30 de Novembro de 2000.

OBSERVATÓRIO DO TURISMO DO PANTANAL DE CORUMBÁ. II Relatório da Pesca Retrato do Segmento. Disponível em: https://drive.google.com/file/d/ 0B5r4Bnx5xHYKbXVDTXRWdFVVU3c/view . Acesso em: 22/9/2016.

OLIVEIRA, R.R.; MONTEZUMA, R.C.M. História ambiental e ecologia da paisagem. Mercator: Revista de Geografia da UFC, vol. 9, n.19, mai/ago, 2010, pp. 117-128.

PEREIRA, B.E.; DIEGUES, A.C.S.A. Conhecimento de populações tradicionais como possibilidade de conservação da natureza: uma reflexão sobre a perspectiva da etnoconservação. Desenvolvimento e Meio Ambiente, n. 22, p. 37-50, jul./dez. 2010.

PORTAL DA PREFEITURA DE CORUMBÁ MS. Hospedagem rural. Disponível em: http://www.pmcorumba.com.br/site/turista/4/hospedagem-rural/93/ . Acesso em: 3 setembro 2016.

RELATÓRIO FINAL. Programa de Ações Estratégicas para o Gerenciamento Integrado do Pantanal e Bacia do Alto Paraguai: Relatório Final/Agência Nacional de Águas - ANA ... [et al.]. - Brasília: TDA Desenho \& Arte Ltda., 2004.

RIBEIRO, D.R.; LIMA, J.S.P. Estradas parque do ponto de vista da infraestrutura de transportes. XIII Fórum Ambiental da Alta Paulista.Tupã, 26 a 28 de julho de 2017. Disponível em https://www.amigosdanatureza.org.br/eventos/data/inscricoes/1915/ form10448461.pdf. Acessado em 29 de junho de 2019

RIBEIRO, M.A.S., Entre os ciclos de cheias e vazantes a gente do Pantanal produz e revela geografias. Campinas, SP : [s.n.], 2014.

RIBEIRO, M.A.; VARGAS, I.A.; ARAÚJO, A.P.C. Estrada-parque pantanal, MS, Brasil: paisagens ressignificadas, modos de vida alterados. Revista Geográfica de América Centra/ Número Especial EGAL, Costa Rica II Semestre 2011 pp. 1-11

SILVA, J.S.V.; ABDON, M.M. Delimitação do Pantanal brasileiro e suas sub-regiões.

Pesq. Agropec. Bras., Brasília, v.33, Número Especial, p1703-1711, out. 1998. 
SORIANO, A.J.S. Estrada-parque: proposta para uma definição. Tese (Doutorado em Geografia). Programa de Pós-Graduação em Geografia. Universidade Paulista Julio de Mesquita, Rio Claro. 2006.

TRICHÊS, G. et al. Certificação rodovias verdes no Brasil: proposição de metodologia. $7^{\circ}$.Congresso Brasileiro de Rodovias e Concessões. Foz do Iguaçu, 2011. Disponível em: http://cbrcbrasvias.com.br/palestras/arquivos/TC0036-1.PDF . Acessado em 20 de maio de 2019.

TROLL, C. Landscape Ecology. Delf: Publ. UNESCO, 1966

TROLL, C. Geoecology of the mountanious regions of the tropical americas. Proceedings of the UNESCO, Mexican Symposium. p.1-3, 1968.

VARGAS, I.A.; HEMANN, A. Sentir o "Paraiso" no Pantanal: reflexões sobre percepção e valoração ambientais. Desenvolvimento em Meio Ambiente, n.7, p.131-143, jan./jun. 2003. Editora UFPR.

XIMENES, D.S.S. A biodiversidade e o turismo regional fatores de resiliência urbana nas cidades de cabreuva, itu e salto. Revista LABVERDE $n^{\circ} 7$ - Artigo n`02. 2013.

WU, J. Landscape sustainability science: ecosystem services and human well-being in changing landscapes. Landscape Ecology, (28), julho de 2013, p. 999-1023.

WU, J. Landscape of culture and culture of landscape: does landscape ecology need culture?. Landscape Ecology, (21) agosto de 2010. P. 1147-1150.

Nota:

1 Corixos: denominação regional do Pantanal atribuída aos pequenos riachos permanentes que ligam as baías (Dicionário Geológico-Geomorfológico, 2008).

Marcelo Silva de Oliveira: Universidade Católica Dom Bosco, Campo Grande, MS, Brasil

E-mail: bugre@terra.com.br

Link para o currículo Lattes: http://lattes.cnpq.br/3305712609593434

Cleonice Alexandre Le Bourlegat: Universidade Católica Dom Bosco, Campo Grande, MS, Brasil

E-mail: clebourlegat@ucdb.br

Link para o currículo Lattes: http://lattes.cnpq.br/4742629741764407

Data de submissão: 16 de novembro de 2018

Data de recebimento de correções: 25 de fevereiro de 2019

Data do aceite: 21 de agosto de 2019

Avaliado anonimamente 